\title{
Chapter 18 \\ High Levels of Saturated Fatty Acids may \\ Exacerbate the Pathogenesis of Primary Sjögren's Syndrome
}

\author{
Yosuke Shikama, Naozumi Ishimaru, Yasusei Kudo, Rieko Arakaki, \\ Yukiko Bando, Nanako Aki, Yoshio Hayashi, and Makoto Funaki
}

\begin{abstract}
Obesity and type 2 diabetes (T2D) are characterized by decreased insulin sensitivity and higher concentrations of free fatty acids (FFAs) in the serum. Among FFAs, saturated fatty acids, such as palmitate, have been reported to play a role in obesity-associated inflammation. Primary Sjögren's syndrome (SS) is an autoimmune disease characterized by infiltration of inflammatory mononuclear cells and destruction of epithelial cells in salivary and lacrimal glands. Although epidemiological studies have suggested a link between primary SS and dyslipidemia or T2D, little is known about the clinical significance of elevated serum level of FFAs in primary SS. In salivary gland epithelial cells of patients with primary SS, interleukin (IL)- 6 production and $\alpha$-fodrin degradation are increased. IL- 6 is one of the pro-inflammatory cytokines, and the cleavaged $\alpha$-fodrin serves as an auto-antigen. In this study, we demonstrate that palmitate, but not unsaturated fatty acids, induces IL-6 production and $\alpha$-fodrin degradation in human salivary gland epithelial cell lines. However, palmitate did not induce these responses in keratinocytes. Taken together, these results suggest that higher levels of saturated fatty acids may promote the severity of primary SS.
\end{abstract}

Keywords Apoptosis • Interleukin-6 • Lipids • Palmitate • Sjögren’s syndrome - $\alpha$-fodrin

Y. Shikama $(\bowtie) \cdot$ Y. Bando $\bullet$ N. Aki $\bullet$ M. Funaki

Clinical Research Center for Diabetes, Tokushima University Hospital, 2-50-1

Kuramoto-cho, Tokushima 770-8503, Japan

e-mail: shikama@tokushima-u.ac.jp

N. Ishimaru $\bullet$ Y. Kudo • R. Arakaki $・$ Y. Hayashi

Department of Oral Molecular Pathology, Institute of Health Biosciences,

The University of Tokushima Graduate School, 3-18-15 Kuramoto-cho,

Tokushima 770-8504, Japan 


\subsection{Introduction}

Obesity is rapidly prevailing and is one of the major threats to global health these days. The epidemic of obesity has resulted in dramatic increases in the prevalence of obesity-associated diseases including type 2 diabetes (T2D) [1]. It has been known that the level of free fatty acids (FFAs) in the blood is elevated in T2D patients as well as animal models of T2D [2], which is attributable to enhanced lipolysis in adipocytes and increased consumption of dietary lipids [3]. It has been demonstrated that saturated fatty acids (SFAs), such as palmitate and stearate, induce inflammatory responses presumably activation of Toll-like receptor (TLR) 4 and its downstream signaling pathway [4-6]. TLRs are one of the pattern recognition receptors that play a key role in induction of innate and adaptive immune response through recognition of pathogen-associated molecular patterns (PAMPs) of microbes [7]. Furthermore, excess amount of FFAs in the blood can lead to proinflammatory response and intracellular lipid accumulation, which could also result in cellular dysfunction, so-called 'lipotoxicity'. Lipotoxicity has been reported in pancreatic $\beta$ cells, hepatocytes, cardiomyocytes, and skeletal muscle cells [8], but hardly reported in epithelial cells such as epithelial cells in exocrine glands.

Primary Sjögren's syndrome (SS) is an autoimmune disorder that is characterized by chronic dysfunction and destruction of exocrine glands, mainly the salivary and lacrimal glands associated with chronic lymphocytic infiltrating lesions, that leads to persistent dryness of eyes and mouth. Emerging evidence suggests that salivary gland epithelial cells also actively participate in the inflammatory process of SS [9]. For instance, interleukin (IL)-6, which is one of proinflammatory cytokines known to serve as a B cell growth factor and a vital factor for plasma cell survival [10], is upregulated in salivary gland epithelial cells of SS patients [11-13]. IL-6 production is induced by activation of intracellular signaling cascades including the mitogen-activated protein kinase (MAPK) pathways and the nuclear factor- $\mathrm{B}(\mathrm{NF}-\kappa \mathrm{B})$ pathway [14]. It has been also reported that $\alpha$-fodrin, which is a ubiquitously-expressed heterodimeric calmodulin-binding protein, is cleaved during apoptosis by caspase- 3 or $\mu$-calpain to produce $120 \mathrm{kDa}$ fragments in salivary gland ductal epithelial cells. These $\alpha$-fodrin-derived $120 \mathrm{kDa}$ fragments have been shown to serve as an auto-antigen in murine and human primary SS $[15,16]$.

An association between obesity-related metabolic disorders and SS was first reported in "pseudo-Sjögren syndrome" [17, 18], which was followed by an experimental study in mice that reported a link between SS and diabetes [19]. Moreover, it was recently reported that primary SS patients had significantly higher incidence of metabolic disorders, such as T2D [20, 21]. These observations described above led us to hypothesize that SFAs may induce IL-6 secretion, lipotoxicity, and $\alpha$-fodrin degradation in human salivary gland epithelial cells. In this report, we provide evidence that SFAs, but not unsaturated fatty acids, induce IL-6 secretion mediated by activation of p38 MAPK and NF- $\mathrm{BB}$ activation. 
Palmitate also induces intracellular lipid accumulation and apoptosis, and $\alpha$-fodrin degradation. However, these SFAs-dependent responses observed in salivary gland epithelial cells are not common among epithelial cells in other type of tissues. These observations implicate that salivary gland epithelial cells are susceptible to palmitate-induced IL-6 secretion, lipotoxicity, and $\alpha$-fodrin degradation, which could exacerbate the pathogenesis of primary SS in salivary glands.

\subsection{Materials and Methods}

\subsubsection{Reagents}

Fetal bovine serum (FBS) and penicillin/streptomycin were purchased from Life Technologies (Carlsbad, CA). Dulbecco's modified Eagle's medium (DMEM), FFAs, SP600125, SB203580, and BAY11-7082 were obtained from Sigma-Aldrich (St. Louis, MO). FFA-free bovine serum albumin (BSA) was obtained from Merck (Darmstadt, Germany). A stock solution of FFA was prepared and conjugated with BSA as described previously [22] with slight modifications as follows; FFA was dissolved at a concentration of $100 \mathrm{mM}$ in $0.1 \mathrm{~mol} / \mathrm{L} \mathrm{NaOH}$ at $90{ }^{\circ} \mathrm{C}$ for $20 \mathrm{~min}$, which was then diluted 10 -fold with $10 \%$ BSA solution pre-incubated at $55^{\circ} \mathrm{C}$. The solution was vortexed for $10 \mathrm{~s}$ and incubated at $55^{\circ} \mathrm{C}$ for additional $10 \mathrm{~min}$. FFA solution of $10 \mathrm{mmol} / \mathrm{L}$ FFA with $10 \% \mathrm{BSA}$ and 10\%BSA control solutions were prepared just before experiments. FFA preparations were checked for LPS contamination using Limulus Color KY Single Test (Wako).

\subsubsection{Antibodies}

Anti-glyceraldehyde-3-phosphate dehydrogenase (GAPDH), anti-IкB $\alpha$, antiphospho-IкB $\alpha$ (Ser32/36), anti-p38 MAPK, antiphospho-p38 MAPK (Thr180/ Tyr182), anti-SAPK/JNK, antiphospho-SAPK/JNK (Thr183/Tyr185), anticaspase-3, and anti-calpain1 ( $\mu$-type) antibodies were purchased from Cell Signaling Technology (Danvers, MA). Anti- $\alpha$-fodrin was obtained from Enzo Life Sciences (Plymouth Meeting, PA).

\subsubsection{Cells and Cell Culture}

A human parotid gland ductal epithelial cell line HSY and a human submandibular gland ductal epithelial cell line HSG were developed as described previously $[23,24]$. A human oral squamous carcinoma cell line HSC-2 was provided by 
Japanese Collection of Research Bioresources Cell Bank (Osaka, Japan). An immortalized human keratinocyte cell line $\mathrm{HaCaT}$ was obtained from Dr. Norbert E. Fusenig (German Cancer Research Center, Heidelberg, Germany). Cells were cultured in DMEM supplemented with $10 \%$ FBS, $100 \mathrm{U} / \mathrm{mL}$ penicillin and $100 \mu \mathrm{g} /$ $\mathrm{mL}$ streptomycin at $37{ }^{\circ} \mathrm{C}$ with a humidified atmosphere of $5 \% \mathrm{CO}_{2}$. Cells were serum starved $(0.1 \% \mathrm{BSA})$ overnight for experiments.

\subsubsection{RNA Isolation and RT-PCR}

Cells were lysed in $1 \mathrm{~mL}$ of ISOGEN (Nippon Gene, Tokyo, Japan), and total RNA was extracted as described in the manufacturer's instructions. One $\mu \mathrm{g}$ of total RNA was reverse transcribed into cDNA with a first-strand cDNA synthesis kit (Roche Diagnostics, Indianapolis, IN). Primers used were as follows: TLR4 (forward) 5'-TGGATACGTTTCCTTATAAG-3' and (reverse) 5'-GAAATGGAGGCACCCCTTC-3'; IL-6 (forward) 5'-AAGCCAGAGCTGTG CAGATGAGTA-3' and (reverse) 5'-TGTCCT GCAGCCACTGGTTC-3'; GAPDH (forward) 5'-GCCACATCGCTCAGACAC-3' and (reverse) 5'-CTCGC TCCTGGAAGATGG- ${ }^{\prime}$. PCR products were then subjected to agarose gel electrophoresis and analyzed with an LAS-3000 UV Lumino-image analyzer (Fujifilm, Tokyo, Japan).

\subsubsection{Measurement of IL-6 Production}

Cells were seeded into 96-well plates at a concentration of $1 \times 10^{5}$ cells/well (Orange Scientific, Braine-l'Alleud, Belgium) and incubated overnight. After treating the cells as described in the figure legends, the medium was collected. The amount of IL-6 in the medium was determined using a human IL-6 ELISA kit (Thermo Scientific, Rockford, IL) according to the manufacturer's instructions.

\subsubsection{Immunoblotting}

After treating the cells as described in the figure legends, cells were rinsed three times with ice-cold phosphate-buffered saline (PBS) and lysed in radioimmunoprecipitation assay buffer $[50 \mathrm{mM}$ Tris, $150 \mathrm{mM} \mathrm{NaCl}, 1 \%$ sodium deoxycholate, $1 \%$ Triton X-100, $0.1 \%$ sodium dodecyl sulfate, $1 \mathrm{mM}$ sodium orthovanadate, and $1 \%$ protease inhibitor cocktail (Sigma) (pH 7.5)]. Cell lysates obtained by centrifugation at $15,000 \times g$ and $4{ }^{\circ} \mathrm{C}$ for 10 min were subjected to SDS-PAGE and transferred to polyvinylidene diflouride (PVDF) membranes as described previously [25]. In some experiments, antibodies were diluted in Can Get 
Signal (Toyobo, Osaka, Japan). Immunoblotting was performed with an ECL PLUS system according to the manufacturer's instructions, and analyzed by a LAS-3000 UV Lumino-image analyzer (Fujifilm).

\subsubsection{Oil Red O Staining}

To evaluate intracellular lipid accumulation, cells were stained with Oil Red $\mathrm{O}$ as described previously [26]. Briefly, after treating the cells, cells were washed three times with iced PBS and fixed with $4 \%$ paraformaldehyde. Fixed cells were washed again with PBS and stained with Oil Red O solution $(1.8 \mathrm{mg} / \mathrm{mL}$ Oil Red O in $60 \%$ ethanol) for $15 \mathrm{~min}$ at room temperature. After cells were washed again with PBS, cells were observed on a phase contrast microscope (Olympus, Tokyo, Japan).

\subsubsection{Cell Viability Assay}

Cell viability was assessed by measuring a mitochondrial activity in reducing 2-(2-methoxy-4-nitrophenyl)-3-(4-nitrophenyl)-5-(2,4-disulfophenyl)-2H-tetrazolium monosodium salt (WST-8) to formazan using a Cell Counting Kit-8 (Dojindo, Kumamoto, Japan) according to the manufacturer's instructions. The amount of formazan was quantified using a microplate reader (BioRad, Hercules, CA).

\subsubsection{Annexin V-FITC/Propidium Iodide (PI) Staining}

Palmitate-induced apoptosis of salivary gland cells was evaluated by an Annexin V-FITC/PI staining with a TACS Annexin V-FITC Apoptosis Detection Kit (R and D systems, Minneapolis, MN) according to the manufacturer's instructions. After treating the cells as described in the figure legends, fluorescent-positive cells were detected by FACSVerse and analyzed by FACSuite (BD Biosciences, San Diego, CA).

\subsubsection{DAPI Staining}

For detecting apoptosis in HSY cells, they were seeded on Lab-Tek chamber slides (Nunc, Thermo Fisher Scientific, Rochester, NY). After treating the cells as described in the figure legends, cells were washed three times with iced PBS and fixed with $4 \%$ paraformaldehyde followed by staining with 4',6-diamidino-2phenylindole (DAPI) (Invitrogen, Carlsbad, CA). Stained cells were visualized on 
a laser scanning confocal microscope (Carl Zeiss, Gottingen, Germany). Apoptotic cells were morphologically defined as cells with nuclear shrinkage, condensation, and fragmentation.

\subsubsection{Data Analysis}

To confirm the reproducibility of the results, all experiments were conducted at least twice. Experimental values are given as mean \pm standard deviation (SD). The statistical significance of differences was evaluated using a Student's unpaired $t$-test or Dunnett's multiple-comparison test after an analysis of variance (ANOVA) with IBM SPSS Statistics software 19.0 (IBM, Armonk, NY). P values less than 0.05 were considered to be significant.

\subsection{Results and Discussion}

We obtained results as described below. (a) Palmitate treatment induces IL-6 secretion in HSY and HSG cells, but not $\mathrm{HaCaT}$ cells. (b) In salivary gland epithelial cells, saturated fatty acids, but not unsaturated fatty acids, induces IL-6 secretion presumably through activation of NF- $\mathrm{\kappa B}$ and p38 MAPK. (c) It has been documented that lipotoxicity causes apoptosis, which is featured by some morphological changes such as cell shrinkage, cell rounding, and lipid accumulation [8, 27]. Thus, we investigated whether or not palmitate treatment induces morphological changes. Palmitate treatment induced morphological changes which are cell rounding and lipid accumulation in HSY and HSG cells. On the other hand, HSC-2 and $\mathrm{HaCaT}$ cells failed to accumulate lipid droplet after palmitate treatment despite their tendency to round up (Fig. 18.1). (d) Palmitate treatment increases apoptosis of HGY and HSG cells. (e) Palmitate induces a-fodrin degradation and caspase-3 activation in salivary gland epithelial cells. Details were already shown in our report [28]. Moreover, we recently confirmed that, when model mice of primary SS were fed with high-fat diet to elevate the serum level of saturated fatty acids, their salivary glands and lacrimal glands exhibited inflammation significantly more advanced than those observed in model mice fed with normal diet (data not shown). Taken together, these results suggest that higher levels of saturated fatty acids may promote the severity of primary SS.

In conclusion, our data indicate that palmitate may exacerbate the pathogenesis of primary SS. Results presented in this report should encourage further investigations on relationship between metabolic-related disorders and autoimmune diseases such as primary SS. 

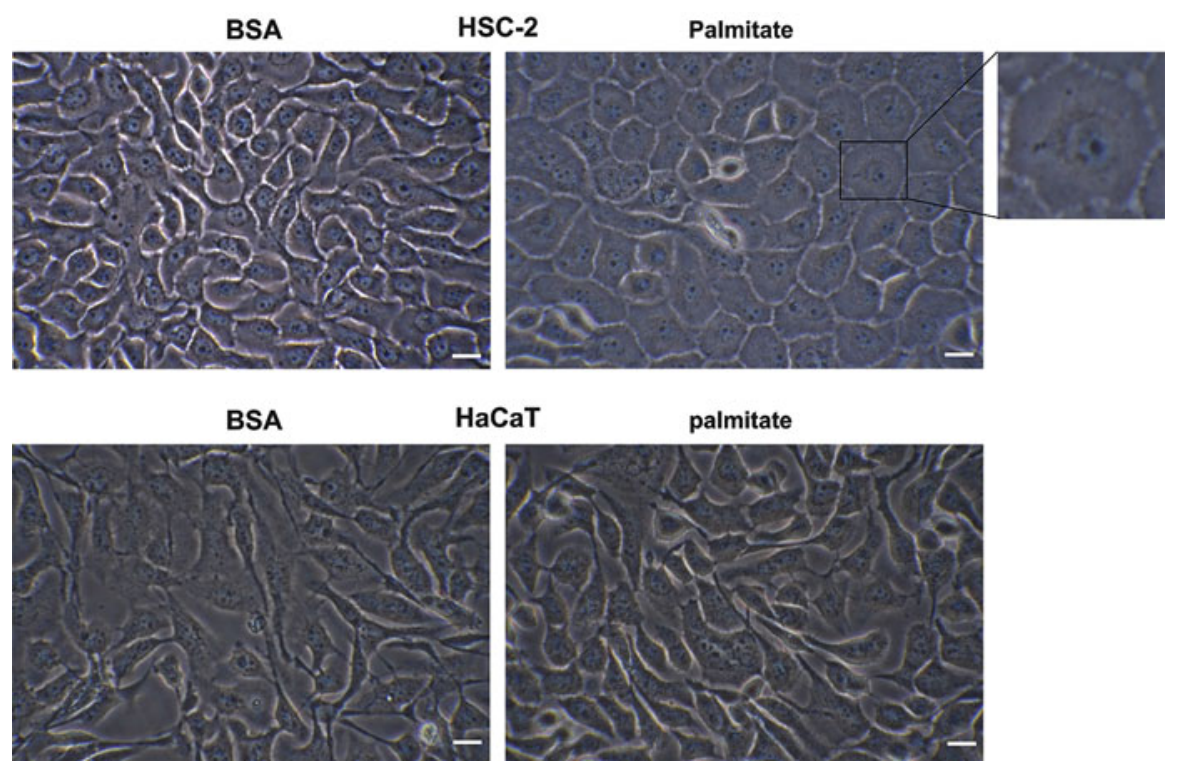

Fig. 18.1 HSY cells and HSG cells, but not HSC-2 cells and HaCaT cells, exhibited palmitateinduced cell shape change and lipid accumulation. A representative image $(\times 400)$ of cells treated with control (BSA) or palmitate $(500 \mu \mathrm{M})$ for $24 \mathrm{~h}$. Arrow heads indicate cytoplasmic lipid droplets. Scale bars $=20 \mu \mathrm{m}$

Open Access This chapter is distributed under the terms of the Creative Commons Attribution Noncommercial License, which permits any noncommercial use, distribution, and reproduction in any medium, provided the original author(s) and source are credited.

\section{References}

1. Hill JO. Understanding and addressing the epidemic of obesity: an energy balance perspective. Endocr Rev. 2006;27(7):750-61.

2. Boden G. Interaction between free fatty acids and glucose metabolism. Curr Opin Clin Nutr Metab Care. 2002;5(5):545-9.

3. Cnop M. Fatty acids and glucolipotoxicity in the pathogenesis of type 2 diabetes. Biochem Soc Trans. 2008;36(Pt 3):348-52.

4. Eguchi K, Manabe I, Oishi-Tanaka Y, Ohsugi M, Kono N, Ogata F, et al. Saturated fatty acid and TLR signaling link beta cell dysfunction and islet inflammation. Cell Metab. 2012;15 (4):518-33.

5. Erridge C, Samani NJ. Saturated fatty acids do not directly stimulate Toll-like receptor signaling. Arterioscler Thromb Vasc Biol. 2009;29(11):1944-9.

6. Maloney E, Sweet IR, Hockenbery DM, Pham M, Rizzo NO, Tateya S, et al. Activation of NF-kappaB by palmitate in endothelial cells: a key role for NADPH oxidase-derived superoxide in response to TLR4 activation. Arterioscler Thromb Vasc Biol. 2009;29(9):1370-5.

7. Akira S, Uematsu S, Takeuchi O. Pathogen recognition and innate immunity. Cell. 2006;124 (4):783-801.

8. Kusminski CM, Shetty S, Orci L, Unger RH, Scherer PE. Diabetes and apoptosis: lipotoxicity. Apoptosis. 2009;14(12):1484-95. 
9. Manoussakis MN, Kapsogeorgou EK. The role of epithelial cells in the pathogenesis of Sjogren's syndrome. Clin Rev Allergy Immunol. 2007;32(3):225-30.

10. Minges Wols HA, Underhill GH, Kansas GS, Witte PL. The role of bone marrow-derived stromal cells in the maintenance of plasma cell longevity. J Immunol. 2002;169(8):4213-21.

11. Anaya JM, Talal N. Sjogren's syndrome comes of age. Semin Arthritis Rheum. 1999;28 (6):355-9.

12. Fox RI, Kang HI, Ando D, Abrams J, Pisa E. Cytokine mRNA expression in salivary gland biopsies of Sjogren's syndrome. J Immunol. 1994;152(11):5532-9.

13. Sekiguchi M, Iwasaki T, Kitano M, Kuno H, Hashimoto N, Kawahito Y, et al. Role of sphingosine 1-phosphate in the pathogenesis of Sjogren's syndrome. J Immunol. 2008;180 (3):1921-8.

14. Ajibade AA, Wang Q, Cui J, Zou J, Xia X, Wang M, et al. TAK1 negatively regulates NF-kappaB and p38 MAP kinase activation in Gr-1 + CD11b + neutrophils. Immunity. 2012;36(1):43-54.

15. Haneji N, Nakamura T, Takio K, Yanagi K, Higashiyama H, Saito I, et al. Identification of alpha-fodrin as a candidate autoantigen in primary Sjogren's syndrome. Science. 1997;276 (5312):604-7.

16. Miyazaki K, Takeda N, Ishimaru N, Omotehara F, Arakaki R, Hayashi Y. Analysis of in vivo role of alpha-fodrin autoantigen in primary Sjogren's syndrome. Am J Pathol. 2005;167 (4):1051-9.

17. Goldman JA, Julian EH. Pseudo-Sjogren syndrome with hyperlipoproteinemia. JAMA. 1977;237(15):1582-4.

18. Kaltreider HB, Talal N. Bilateral parotid gland enlargement and hyperlipoproteinemia. JAMA. 1969;210(11):2067-70.

19. Robinson CP, Yamachika S, Alford CE, Cooper C, Pichardo EL, Shah N, et al. Elevated levels of cysteine protease activity in saliva and salivary glands of the nonobese diabetic (NOD) mouse model for Sjogren syndrome. Proc Natl Acad Sci U S A. 1997;94(11):5767-71.

20. Kang JH, Lin HC. Comorbidities in patients with primary Sjogren's syndrome: a registrybased case-control study. J Rheumatol. 2010;37(6):1188-94.

21. Ramos-Casals M, Brito-Zeron P, Siso A, Vargas A, Ros E, Bove A, et al. High prevalence of serum metabolic alterations in primary Sjogren's syndrome: influence on clinical and immunological expression. J Rheumatol. 2007;34(4):754-61.

22. Cousin SP, Hugl SR, Wrede CE, Kajio H, Myers Jr MG, Rhodes CJ. Free fatty acid-induced inhibition of glucose and insulin-like growth factor I-induced deoxyribonucleic acid synthesis in the pancreatic beta-cell line INS-1. Endocrinology. 2001;142(1):229-40.

23. Shirasuna K, Sato M, Miyazaki T. A neoplastic epithelial duct cell line established from an irradiated human salivary gland. Cancer. 1981;48(3):745-52.

24. Yanagawa T, Hayashi Y, Nagamine S, Yoshida H, Yura Y, Sato M. Generation of cells with phenotypes of both intercalated duct-type and myoepithelial cells in human parotid gland adenocarcinoma clonal cells grown in athymic nude mice. Virchows Arch B Cell Pathol Incl Mol Pathol. 1986;51(3):187-95.

25. Shikama Y, Kuroishi T, Nagai Y, Iwakura Y, Shimauchi H, Takada H, et al. Muramyldipeptide augments the actions of lipopolysaccharide in mice by stimulating macrophages to produce pro-IL-1beta and by down-regulation of the suppressor of cytokine signaling 1 (SOCS1). Innate Immun. 2011;17(1):3-15.

26. Lin CL, Huang HC, Lin JK. Theaflavins attenuate hepatic lipid accumulation through activating AMPK in human HepG2 cells. J Lipid Res. 2007;48(11):2334-43.

27. Maestre I, Jordan J, Calvo S, Reig JA, Cena V, Soria B, et al. Mitochondrial dysfunction is involved in apoptosis induced by serum withdrawal and fatty acids in the beta-cell line INS-1. Endocrinology. 2003;144(1):335-45.

28. Shikama Y, Ishimaru N, Kudo Y, Bando Y, Aki N, Hayashi Y, et al. Effects of free fatty acids on human salivary gland epithelial cells. J Dent Res. 2013;92(6):540-6. 